Original Research Paper

\title{
Critical Study of Several MPPT Techniques for Photovoltaic Systems
}

\author{
${ }^{1}$ Bennacer El Hassouni, ${ }^{2}$ A. Haddi and ${ }^{1}$ A.G. Amrani \\ ${ }^{1}$ Polydisciplinary Faculty of Larache, Abdelmalek Essaadi University, Larache, Morocco \\ ${ }^{2}$ ENSA Tangier, Laboratory of Innovative Technologies (LTI) Tangier, \\ Abdelmalek Essaadi University, Tétouan, Morocco
}

Article history

Received: 31-03-2019

Revised: 25-04-2019

Accepted: 18-05-2019

Corresponding Author:

Bennacer El Hassouni

Polydisciplinary Faculty of

Larache, Abdelmalek Essaadi

University, Larache, Morocco

E-mail: bennacer.elhassouni@gmail.com

\begin{abstract}
This paper presents a critical study of Maximum Power Point Tracking (MPPT) techniques for photovoltaic systems. After a brief introduction of the key factors for power extraction of photovoltaic panels, a review of commonly used MPPT techniques is presented and detailed with a holistic approach. Then, a comparison of these techniques is made according to several parameters such as robustness, response time, cost ... In the last part, the advantages and disadvantages of each of the MPPT techniques considered are presented. This article can serve as a quick guide to panel selection and MPPT technique for specific applications.
\end{abstract}

Keywords: Maximum Power Point Tracking, Boost Converter, Photovoltaic Generator

\section{Introduction}

Oil and fossil fuel reserves are falling day after day due to abusive and non-standardized use. Several countries import a large part of their energy needs from abroad. In Morocco, $88.5 \%$ of the necessary energy resources are imported from abroad (Wikipedia).

Renewable energies, especially photovoltaics, have had a great advantage in recent decades. This is why many researchers and scientists have conducted a great deal of research to improve and promote this energy (WBG, 2017).

Oil and fossil fuel reserves decline day by day as a result of misuse and non-standard use. Several countries import most of their energy demand from abroad. In Morocco, 88, 5\% of essential energy is imported from abroad (Wikipedia). Renewable energy sources, especially photovoltaic power generation, have had great advantages in recent decades. That is why many researchers and scientists have carried out a lot of research to improve and promote this energy (WBG, 2017).

In addition, these energies provide a good opportunity to reduce the impact of global warming. Among them, the process of manufacturing photovoltaic systems has been improving over the last decade and photovoltaic systems have become an interesting solution. Specifically, photovoltaic systems include photovoltaic cell arrays, choppers (mainly DC/DC stepdown converters or boosters), MPPT control systems and storage and/or network connectivity devices. Various efforts have been made to improve the efficiency of these systems. However, since solar energy is diffused (approximately $1 \mathrm{~kW} / \mathrm{m}^{2}$ ) and the efficiency of photovoltaic cells is theoretically limited to $19 \%$, it is necessary to strengthen energy transfer. This includes the design of photovoltaic systems and energy management through the search for Maximum Power Points (MPP). MPPT (Faranda and Leva, 2008; Hohm and Ropp, 2000) contains a large number of publications, which are not easy to understand their differences and evaluate their performance.

The main contribution of this paper is to present key research on MPPT technology: first, we introduce photovoltaic theory and emphasize the main parameters of the photovoltaic system to focus on the key elements of MPPT. This article describes some of the most common MPPT technologies and describes their advantages and disadvantages. However, the latest improvements in MPPT studies are not taken into account. Criteria such as efficiency, tracking time, stability, robustness and cost will be introduced to compare the MPPT method chosen. Finally, the simulations will be compared using the Matlab/Simulink ${ }^{\circledR}$ software.

\section{System Configuration}

The systems studied in this work include: Solar panels: Electricity generation by applying solar radiation to its surface. Boost DC-DC Converter: It is a power electronics block, its main objective and power adaptation between the photovoltaic panel and the load. MPPT Control System: Due to the information received 
from the solar panels (current and voltage), the system generates sufficient control to maximize the output power of the photovoltaic genera (Fig. 1).

\section{PV Generator Model}

The photovoltaic generator consists of multiple photovoltaic cells. Each solar cell is essentially a p-n node made of a thin semiconductor wafer. With exposure to sunlight, some photons and energy above the semiconductor band generate electron pairs (Ting-Chung and Shen, 2009). The properties of solar panels are given by the formulas (1) and (Fig. 2) (Kim et al., 2001):

$\left[I=I_{s c}-I_{0}\left\{\exp \left[\frac{q\left(V+R_{s} I\right)}{n k T_{k}}\right]-1\right\}-\frac{V+R_{s} I}{R_{s h}}\right]$

- $\quad I$ : Indicates the output current of the solar panel

- $V:$ is the voltage of the solar panel

- $R_{s h}$ : is the battery bypass resistor

- $R_{s}$ : is the resistance of the battery series

- $q$ : Represents the electronic load (1.60217x10-19 C)

- Isc: is the current generated by light

- $I_{0}$ : is the reverse saturation current

- $\quad N$ : for non-dimensional coefficient

- $\quad K$ : for Boltzmann constant and $T_{k}$ for temperatur

- $\left(\right.$ in $\left.^{\circ} \mathrm{K}\right)$
As shown in Fig. 3, Equation (1) has been used to extract the output characteristics of solar cells.

The curve shows that the characteristic operating point of the generator is closely related to temperature changes, solar radiation and load. Each feature has a point with maximum power, photovoltaic generators work perfectly.

\section{$D C$-DC Converter}

The voltage of the PV DC-DC converter battery is always low, so to produce a generator capable of supplying the load, it is necessary to connect several batteries in parallel. Another thing, to raise the voltage to a sufficient level and adapt the input power to the output, you need to use a DC-DC Boost converter (Hohm and Ropp, 2000).

Figure 4 shows the pulse converter diagram.

The output current and voltage of the boost converter are expressed as Equation 2 and 3 (Liu et al., 2008; Bennacer et al., 2018):

$V s=\frac{V p v}{1-D}$

Where:

$D$ : Represent the duty cycle

$V_{p v}, I_{p v}$ : PV generator voltage and current.

$V_{s}, I_{s}$ : Boost converter voltage and current.

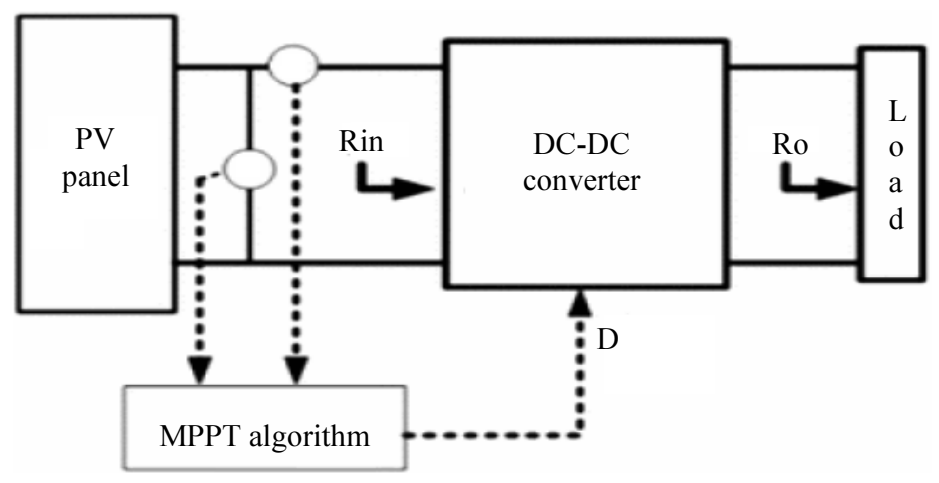

Fig. 1: PV system with MPPT

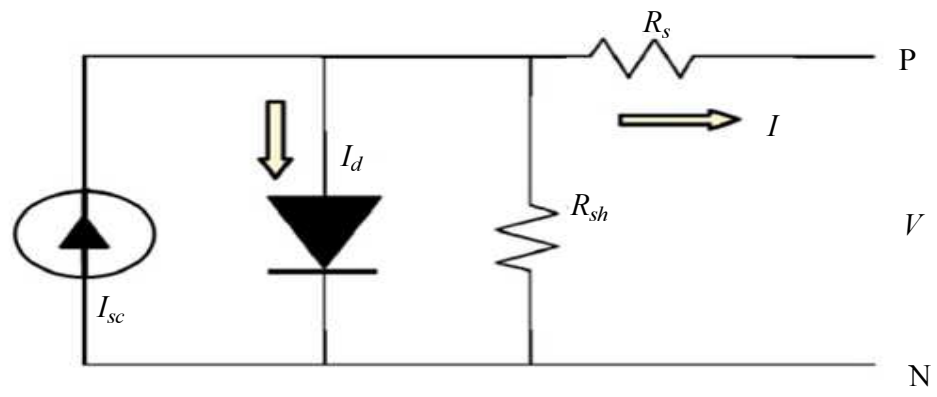

Fig. 2: Equivalent circuit of PV array 


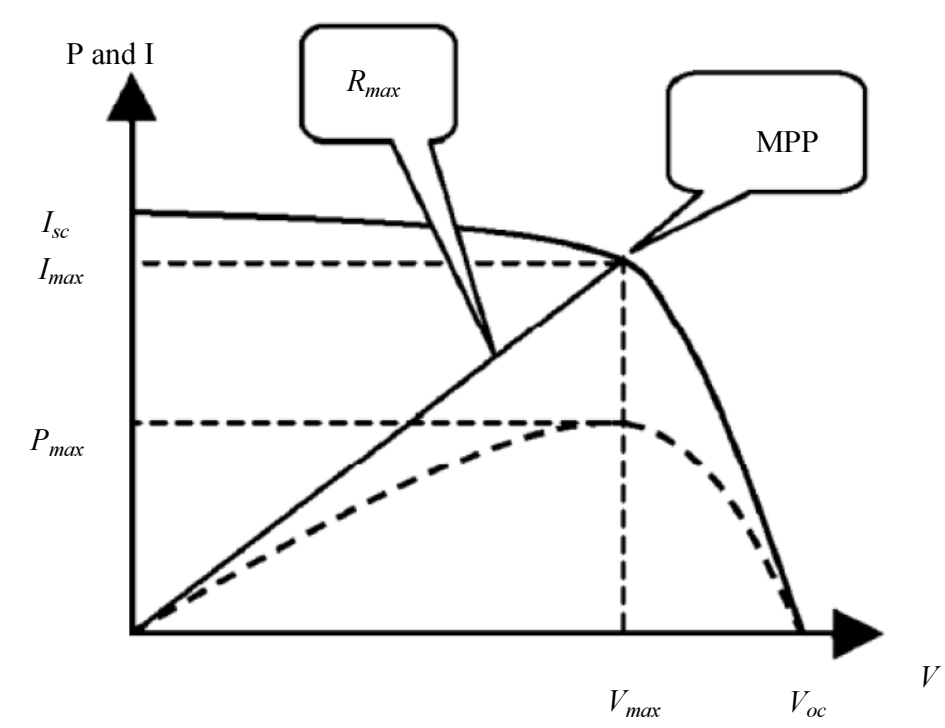

Fig. 3: Output characteristics of a solar cell

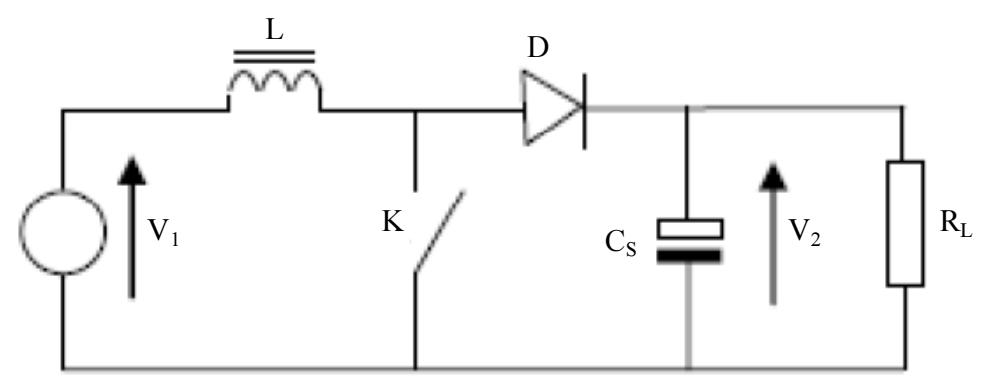

Fig. 4: Equivalent scheme of Boost converter

\section{Presentation of Different MPPT Methods}

In this section we will introduce the principle of operation of the MPPT algorithm that we will deal with, namely:

- Incremental Conductance (InC)

- $\quad$ Perturb and observe (P and O)

- Current sweep Technique (CS)

- $\quad$ Ripple correlation control (RCC)

- Fraction Open Circuit Voltage Technique (FOCV)

- Fractional Short Circuit current (FSCI)

- Fuzzy logic technique

- Neural Network technique

To find the operating point of the system, each algorithm has the task of achieving this condition: the power of the mutation system in relation to the voltage must go to zero (Wang et al., 2010).

\section{Incremental Conductance}

The incremental conductivity method uses the slope of the power characteristics of photovoltaic assemblies for MPP processing (Kim et al., 2001; Liu et al., 2008) Fig. 5. The method is based on the slope of the $P V$ generator power curve is less than zero in MPP (Mekhilef and Kadir, 2010; Azadeh and Mekhilef, 2010), the output power is less than the MPP value is positive and the output power value is less than the $M P P$ value is negative:

$$
\begin{aligned}
& \frac{d P}{d V}=0, \text { at } M P P \\
& \frac{d P}{d V}>0, \text { left of } M P P \\
& \frac{d P}{d V}<0, \text { right of } M P P
\end{aligned}
$$

By using the power formula, $\mathrm{P}=$ V.I, its derivative becomes:

$d P=V . d I+I . d V$

When:

$\frac{d p}{d v}=0$ and $\frac{d(V I)}{d V}=0 ;$ 


$$
I+\frac{V d I}{d V}=0
$$

On comparing the Equation (5) and (6):

$$
I+\frac{V \Delta I}{\Delta V}=0 ; \frac{\Delta I}{\Delta V}=-\frac{I}{V}
$$

So that:

$$
\begin{aligned}
& \frac{\Delta I}{\Delta V}=-\frac{I}{V}, \text { at } M P P ; \\
& \frac{\Delta I}{\Delta V}>-\frac{I}{V}, \text { left of } M P P ; \\
& \frac{\Delta I}{\Delta V}<-\frac{I}{V}, \text { right of } M P P ;
\end{aligned}
$$

Therefore, after MPP, instantaneous conductivity $(\mathrm{I} / \mathrm{V})$ is compared with incremental conductivity $(\Delta \mathrm{I} / \Delta \mathrm{V})$. Vref-the reference voltage for the force of photovoltaic arrays to operate. In MPP, Vref = MPP once it reaches MPP, the PV array operation will remain at this point unless it occurs at "I". The algorithm continues MPP by applying decrement or increment to Vref. The size of the increment or decrement determines the rate at which MPP is tracked.

\section{Benefits}

Incremental methods allow better MPP tracking. Provides an effective solution in a rapidly changing environment. Disadvantages: This method requires complex control circuits.

\section{Perturb and Observe ( $P$ and $O$ )}

$\mathrm{P}$ and $\mathrm{O}$ technique can be achieved by disturbing the reference voltage or current reference signal of solar panels (Wasynczuk, 1983; Hohm and Ropp, 2000; Vikrant, 2005; Abdelsalam et al., 2011). Scaling (Van Wyk and Enslin, 1983) modify the disruption of the duty cycle of the power converter, $\mathrm{P}$ and $\mathrm{O}$ modify the disturbance of the operating voltage of the DC link between the photovoltaic generator and the power converter (Fig. 6). Methods of disturbance and observation at different stages are as follows: 1. 2 . Measure the current and voltage and calculate the power. If the power is constant, again start taking new measurements. If the power decreases or increases, the test voltage changes 4 . The current changes depending on the direction of the voltage change. First, measure the voltage and PV current and calculate the corresponding power P1. The P2 corresponding to the DC-DC converter is calculated taking into account the small voltage disturbance $(\Delta \mathrm{V})$ or duty cycle disturbance $(\Delta \mathrm{D})$ in one direction. Then compare $\mathrm{P} 2$ with $\mathrm{P} 1$. If $\mathrm{P} 2>\mathrm{P} 1$, the disturbance is in the right direction, otherwise it must be reversed. In this way, maximum power points can be identified and the corresponding MPP is calculated. The disturbance changes in the following disturbances are explained in Table 1.
Interference is done this way. The working cycle of the power converter disrupts the current of the photovoltaic generator, thus disrupting the photovoltaic generation.

\section{Disadvantages}

The main disadvantage of $\mathrm{P}$ and $\mathrm{O}$ is occasional deviations from the maximum point of operation, such as cloud dispersion, in rapidly changing atmospheric conditions.

Provides the correct disturbance size for good performance in dynamic response and stable states. Changes quickly, the algorithm gets tracked errors.

\section{Solution}

To overcome this problem, you can use a modified adaptive update technique with a variable disturbance step size. When the power supply changes over a wide range (mainly due to environmental changes), the automatic rotation controller changes the size of the disturbance step to meet the rapid response requirements in the transient phase.

\section{Fraction Open Circuit Voltage Technique (FOCV)}

This is one of the common and simple ways (Schoeman and Van Wyk, 1982; Enslin et al., 1997), where $V_{m p p}$ can be calculated from empirical relationships as follows:

$V_{M P P} \approx K_{1} V_{O C}$

The value of $K_{1}$ varies between 0.78 and $0.92 . K_{1}$ can be calculated by analyzing the photovoltaic system in the range of solar radiation and temperature. The photovoltaic system is turned on for one second at the end of the load to measure $V_{o c_{-}}$. The power converter should be temporarily suspended due to power loss at each measurement. Figure 7 shows the basic flow chart of FOV technology. The main disadvantage of the current method is that since the determination of $V_{M P P}$ is not continuous, it is not possible to follow MPP under irradiated slopes. The place to get to $M P P$ is wrong, because the relationship is just an approximation. Measure Voc and then measure $V_{M P P}$ using the formula above. Repeat this $V_{o c}$ process repeats the sampling every few seconds and updates the $V_{M P P}$ value.

Table 1: Perturbation change in power next perturbation

\begin{tabular}{lll}
\hline Perturbation & Change in power & $\begin{array}{l}\text { Next } \\
\text { perturbation }\end{array}$ \\
\hline Positive & Positive & Positive \\
Positive & Negative & Negative \\
Negative & Positive & Negative \\
Negative & Negative & Positive \\
\hline
\end{tabular}




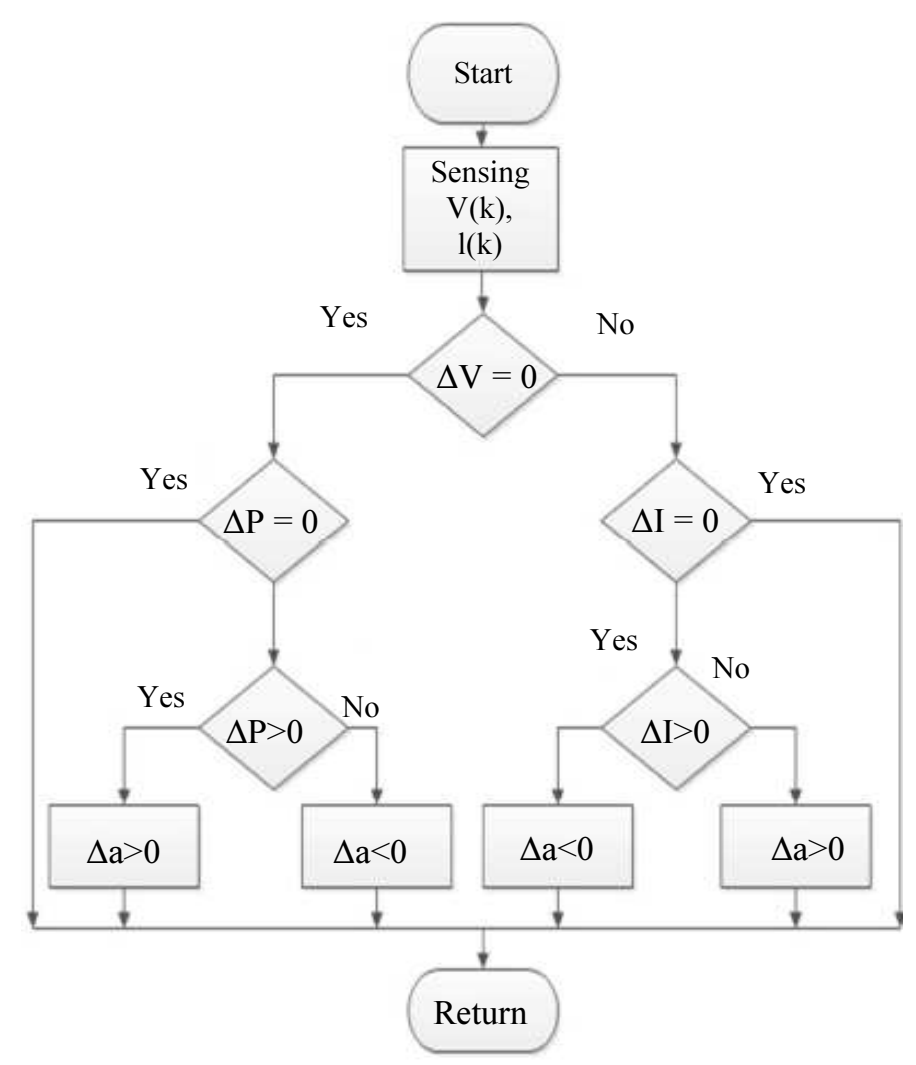

Fig. 5: Block Diagram InC technique

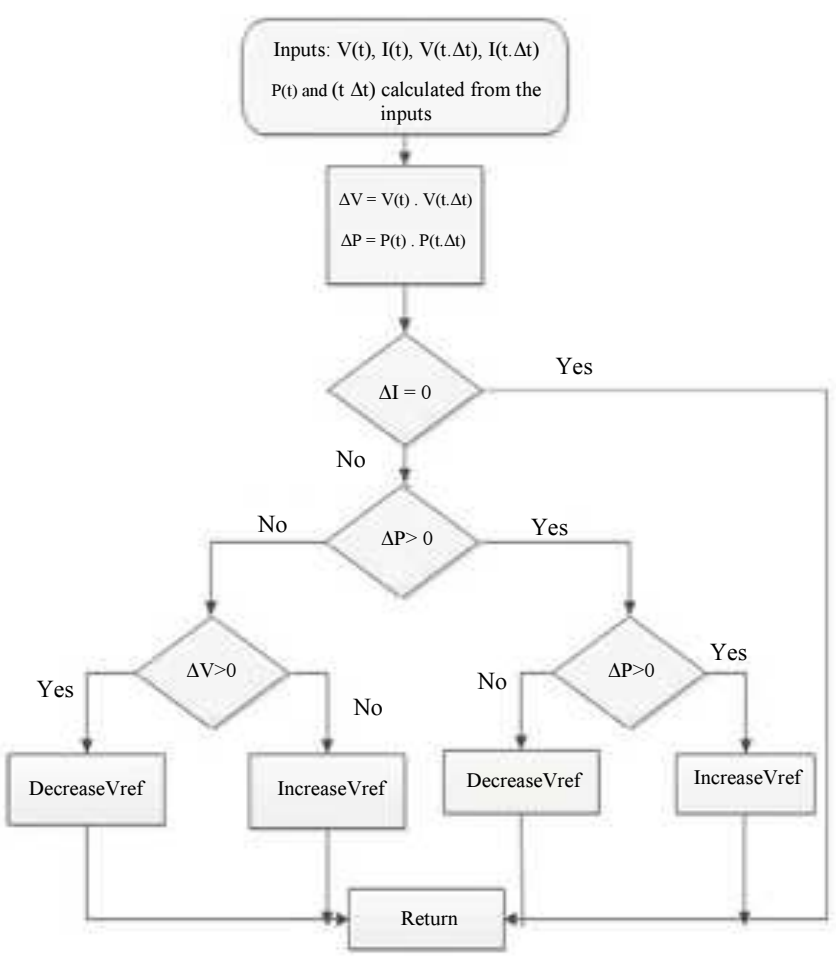

Fig. 6: Block diagram perturb and observe $(\mathrm{P}$ and $\mathrm{O})$ technique 


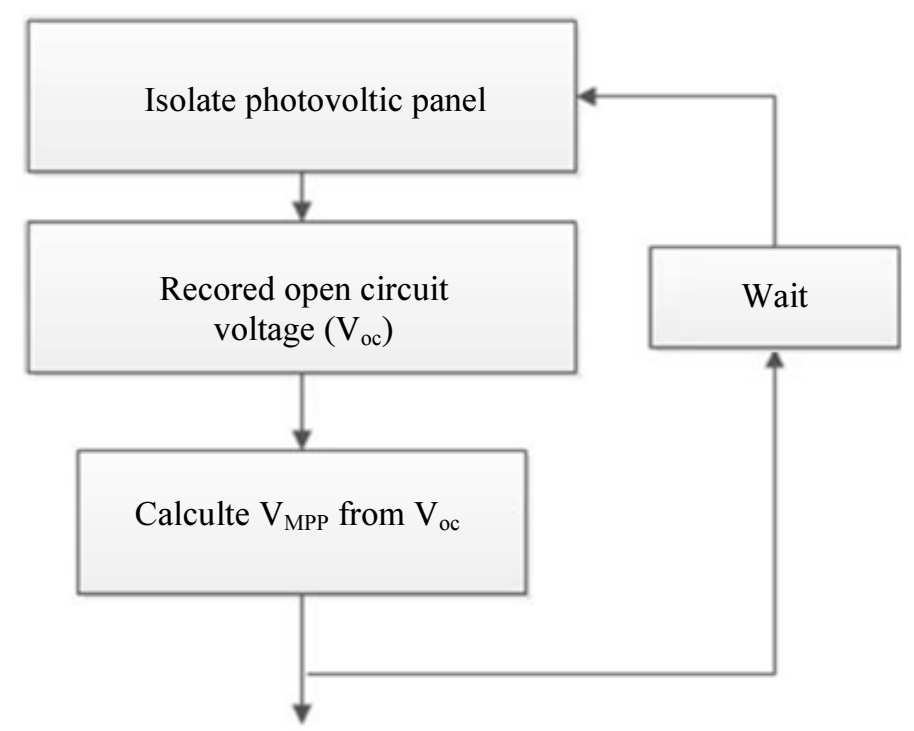

Fig. 7: Block diagram of the open circuit voltage method

Disadvantages: Temporarily lose energy when measuring $V_{o c}$ in an open circuit. The value of $K_{1}$ is no longer valid in the presence of a partial shadow of the photovoltaic generator, which leads to complex implementation and increased energy loss.

\section{Fractional Short Circuit current (FSCI)}

In FSCI technology (Noguchi et al., 2002; Yuvarajan and $\mathrm{Xu}, 2003$ ), non-linear VI characteristics of the photovoltaic system were modeled using mathematical equations, taking into account various environmental conditions and degradation levels of the photovoltaic panels. Figure 8 shows the basic FSCI technology flowchart. Based on feature VI, the mathematical relationship between IMPP and ISC is constructed because IMPP is linearly based on Isc through relationships.

On the basis of characteristics VI, a mathematical relation between $I_{M P P}$ and ISC is constructed, since $I_{M P P}$ is linearly dependent on $I_{s c}$ by a relation:

$$
I_{M P P} \approx K_{S C} \times I_{S C}
$$

Value of the $K_{s c}$ fixed between 0.64 and 0.85

\section{Difficult to Implement}

- $I_{s c}$ measurements during operation are problematic

- The cost of the system increases even more due to the increase. A switch must be added to the power converter circuit to periodically short-circuit the photovoltaic generator to measure $I_{s c}$ using current sensors

- When searching for $I_{s c}$, the power consumption decreases and MPP never fits perfectly

\section{Current Sweep Technique}

Current scanning technology uses the waveform of the photovoltaic generator current to acquire and update the I-V characteristics of photovoltaic assemblies at constant intervals (Bodur and Ermis, 1994). The VMPP is then calculated from the characteristic curve with the same interval. The function selected for the current scan waveform is proportional to its derivative, as follows:

$i(t)=K_{1}\left[\frac{d i(t)}{d t}\right]$

At the maximum power point:

$$
\begin{gathered}
\frac{d p(t)}{d t}=\frac{d[V(t) i(t)]}{d(t)}=0 \\
i(t)\left[\frac{d i(t)}{d t}\right]+V(t)\left[\frac{d i(t)}{d t}\right]=0 ; \\
{\left[K_{1} \frac{d V(t)}{d t}+V(t)\right] \frac{d i(t)}{d t}=0 ;}
\end{gathered}
$$

Solution of Equation (10):

$$
\begin{aligned}
& i(t)=C e \frac{t}{K_{1}} \\
& i(t)=C e^{\frac{t}{K_{1}}} i(t)=\mathrm{I}_{\max } e \frac{-t}{\tau}, \tau=-K_{1} ; C=I_{\max } \cdot S \\
& {\left[\frac{d p(t)}{d i(t)}\right]=V(t)+K_{1}\left[\frac{d v(t)}{d t}\right]=0}
\end{aligned}
$$


After calculating VMPP after the current scan, you can use the above equation to check if the MPP has been reached. The current scan takes about 50 milliseconds, which means the available power is lost. At fixed intervals, the reference points are often updated, so if the scale coefficients $K_{1}$ and $C$ are selected correctly, the performance is obtained accurately.

\section{Ripple Correlation Control (RCC)}

When connected to a power converter, the switching effect of the power converter causes ripple and voltage and current fluctuations to the photovoltaic generator. This leads to the ripple of power of the photovoltaic generator. RCC uses ripple to perform MPPT (Midya et al., 1996). RCC correlates the temporal derivative of the photovoltaic power variable $\mathrm{P}$ with the temporal derivative of the photovoltaic current $I$ or the voltage $V$ and derives the temporal derivative of the photovoltaic power $P$ from the zero-time variable photovoltaic assembly, thus executing $M P P$ :

$i=\frac{d i}{d t}, \dot{V}=\frac{d v}{d t}, \dot{P}=\frac{d p}{d t}$

$\frac{d v}{d t}>0($ or $) \frac{d i}{d t}>0$ and $\frac{d p}{d t}>0$, then $V<M P P($ or $)$

$\frac{d v}{d t}>0($ or $) \frac{d i}{d t} 0$ and $\frac{d p}{d t}<0$, then $V>M P P$,

$I>M P P$

When connected to a power converter, the switching effect of the power converter causes ripple and fluctuation of voltage and current to the photovoltaic generator. This leads to a corrugation of the power of the photovoltaic generator. RCC uses ripple to perform MPPT (Midya et al., 1996). RCC correlates the temporal derivative of PV power variable $P$ over time with the temporal derivative of PV current $I$ or voltage $V$ that varies in time to derive the time derivative of PV power $P$ from the zero time variable $\mathrm{PV}$ set, thus performing $M P P$ :

$$
\begin{aligned}
& d(t)=-K_{3} \int \dot{P} \dot{V} d t \\
& d(t)=K_{3} \int \dot{P} \dot{I} d t
\end{aligned}
$$

This service speed monitoring method ensures continuous monitoring of MPP processing, making RCC a real MPP monitor.

\section{Advantages}

- Real-time implementation can be achieved by simple and economical analog circuits

- It does not require any prior information on the properties of photovoltaic panels

- MPP monitors accurately and quickly, even at different levels of irradiance

\section{Fuzzy logic based MPPT Technique}

Fuzzy logic control is one of the intelligent technologies of MPPT (Salah and Ouali, 2011; Algazar et al., 2012). Fig. 9 and Fig. 10 shows the block diagram of the basic fuzzy control.

They offer excellent performance, fast, unsurpassed response and no constant state fluctuations to cope with rapid temperature and irradiance changes. MPPT based on fuzzy logic does not require an accurate photovoltaic model. Fuzzy logic has two inputs and one output. The two input variables are error $(e)$ and the error change $(\mathrm{Ce})$ in the $K$ th sampling is defined as follows:

$$
\begin{aligned}
& e(k)=\frac{d p}{d v}(k)-\frac{d p}{d v}(k-1) \\
& C e(k)=e(k)-e(k-1)
\end{aligned}
$$

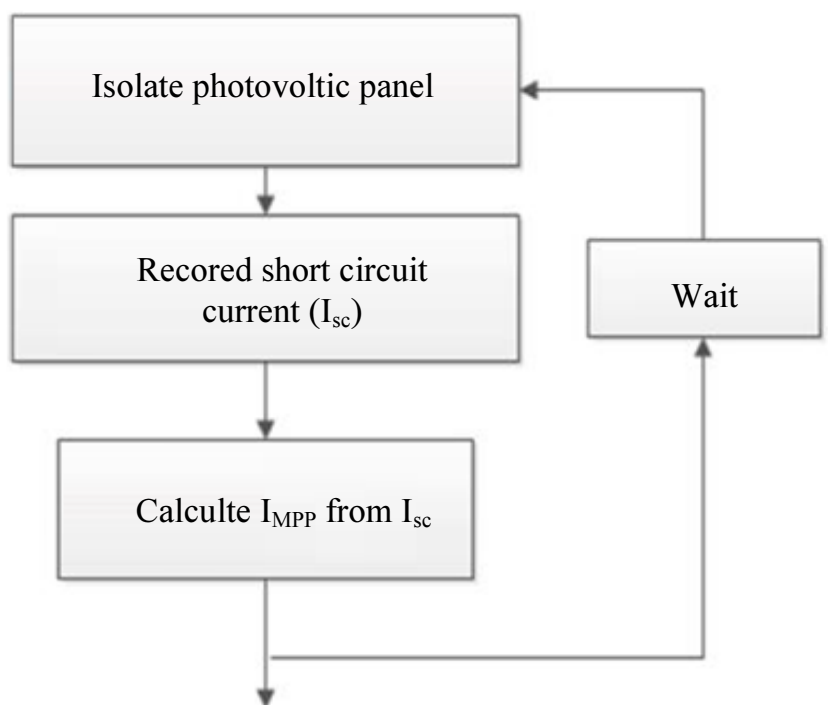

Fig. 8: Block Diagram of the short circuit current method 


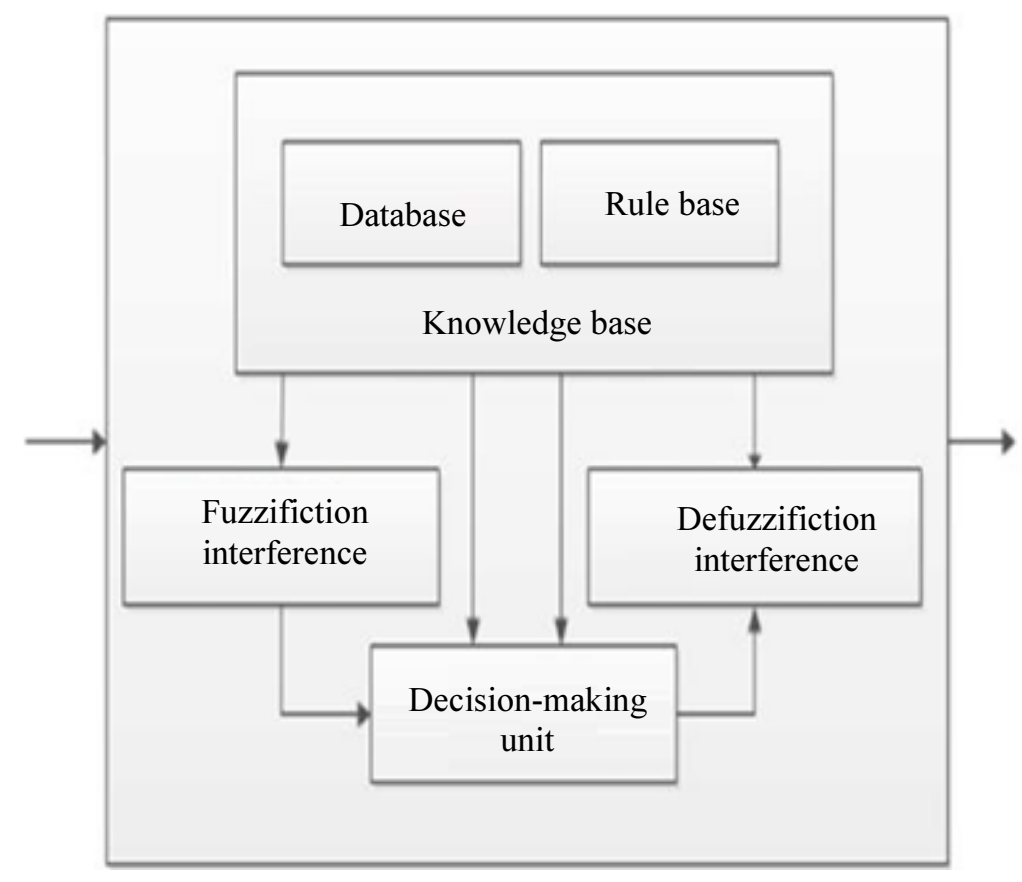

Fig. 9: Block diagram of fuzzy logic and membership functions diagram

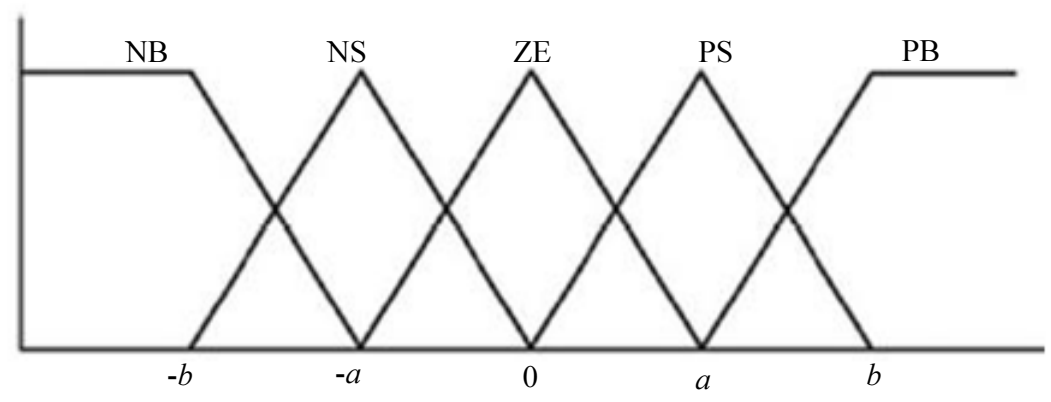

Numerical variable

Fig. 10: Membership function for inputs and output of fuzzy logic controller

$e(k)$-position error of the operating point of the load at the $K$ th instant.

$e(k)$ : error in the position of the load at the point of instant operation $K$. East $(k)$-the direction of movement of this point. The three steps of fuzzy logic control are: numeric fuzzy input variables become language variables based on membership functions. Rules: Make decisions based on the lookup table. Blurring: The output of the fuzzy logic controller is converted from a language variable to a numeric variable. The number of membership functions depends on the accuracy of the controller to be designed, but generally varies between levels 5 and 7. For example, in the chart, five levels are used.

Values $\mathrm{a}$ and $\mathrm{b}$ are based on the range values of numeric variables. When the inputs are $e(K)$ and $C e(K)$, as defined (16) and (17), the output corresponds to the intermediate circuit voltage, $\mathrm{Ce}(K)$. For example, if the operating point is at the right end of the MPP, $e(K)$ is NBs and $C e(K)$ is zero, the reference voltage must be reduced to reach MPP, so dV must be NP (negative). Move the work point to MPP. This provides an analog signal to control the MPP power converter. Table 2 shows the rules defined by seven levels of fuzzy logic controllers and member functions are written as follows: NB-negative large, NM-negative medium, NS-negative small, Ze-zero, PS-small positive, PMpositive mean, PB-taizor.

\section{Neural Network}

Neural network control functions as a black box model and does not require detailed information about the photovoltaic system. Neural networks usually have three layers: Input layer (i/p), hidden and $\mathrm{o} / \mathrm{p}$ (Hiyama et al., 1995; Hiyama and Kitabayashi, 1997). 
Table 2: Rules set for seven levels fuzzy logic controller

\begin{tabular}{llllllll}
\hline E $(\mathrm{K}) \backslash \mathrm{Ce}(\mathrm{K})$ & NB & NM & NS & ZE & PS & PM & PB \\
\hline NB & NB & NB & NB & NB & NM & NS & ZE \\
NM & NB & NB & NB & NM & ZE & PS & PS \\
NS & NB & NB & NM & ZE & PS & PM & PB \\
ZE & NB & NM & NS & ZE & PM & PB & PB \\
PS & NM & NS & ZE & PS & PB & PB & PB \\
PM & NS & ZE & PS & PM & PB & PB & PB \\
PB & ZE & PS & PM & PB
\end{tabular}

Table 3: Comparison of MPPT techniques

\begin{tabular}{|c|c|c|c|c|c|c|c|c|c|c|c|}
\hline MPPT & Application & $\begin{array}{l}\text { Converter } \\
\text { Used }\end{array}$ & $\begin{array}{l}\text { Control } \\
\text { Strategy }\end{array}$ & $\begin{array}{l}\text { PV array } \\
\text { dependent }\end{array}$ & $\begin{array}{l}\text { Analog } \\
\text { /Digital }\end{array}$ & $\begin{array}{l}\text { Parameters } \\
\text { Sensed }\end{array}$ & $\begin{array}{l}\text { Periodic } \\
\text { Timing }\end{array}$ & $\begin{array}{l}\text { Convergence } \\
\text { speed }\end{array}$ & Complexity & Training & Cost \\
\hline $\mathrm{P}$ and $\mathrm{O}$ & Standal one & $\mathrm{DC} / \mathrm{DC}$ & Sampling Method & NO & Both & $\mathrm{V}, \mathrm{I}$ & NO & Varies & Low & $\mathrm{NO}$ & High \\
\hline INC & Standal one & $\mathrm{DC} / \mathrm{DC}$ & Sampling Method & NO & Digital & $\mathrm{V}, \mathrm{I}$ & NO & Varies & Medium & NO & High \\
\hline FOCV & Standal one & $\mathrm{DC} / \mathrm{DC}$ & Indirect Method & Yes & Both & V or I & Yes & Medium & Simple & Yes & Low \\
\hline FSIC & Standal one & $\mathrm{DC} / \mathrm{DC}$ & Indirect Method & Yes & Both & V or I & Yes & Medium & Simple & Yes & Low \\
\hline Current Sweep & Grid & $\mathrm{DC} / \mathrm{AC}$ & Modulation Method & Yes & Digital & I & Yes & Slow & Complex & NO & High \\
\hline $\mathrm{RCC}$ & Standalone & $\mathrm{DC} / \mathrm{DC}$ & Modulation Method & NO & Analog & V or I & NO & Fast & Low & NO & High \\
\hline Fuzzy Logic & Both & Both & Intelligent & Yes & Digital & V or I & Yes & Fast & high & Yes & High \\
\hline Neural Network & Both & Both & Intelligent & Yes & Digital & V or I & Yes & Fast & high & Yes & High \\
\hline
\end{tabular}

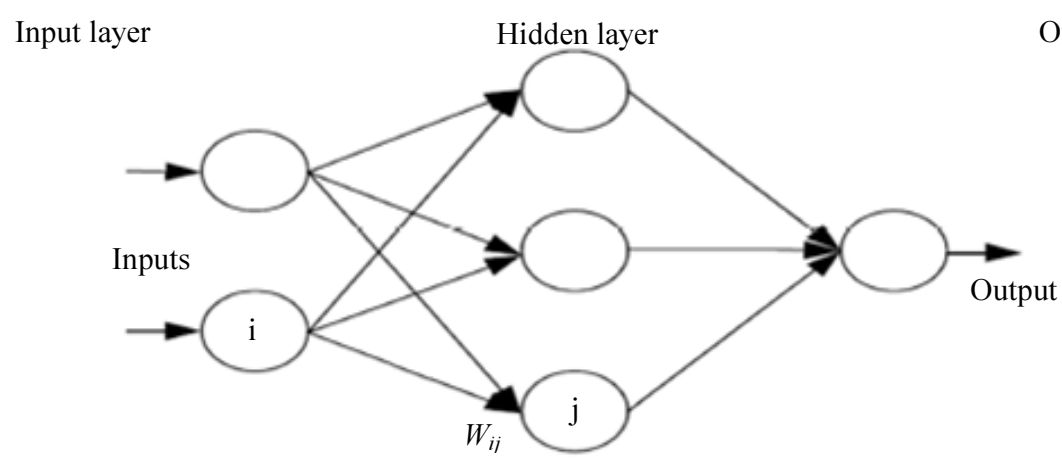

Output layer

Fig. 11: Block diagram of Neural Network

The number of nodes in each layer varies by user Fig. 11. Input variables are photovoltaic generator parameters such as Voc, $\mathrm{I}_{\mathrm{sc}}$, radiation and temperature. The output is usually one or more reference signals, such as the duty cycle used to make the power converter operate in or near MPP. Links between nodes are weighted. To accurately identify MPP, Weights (Wii) must be carefully determined through the training process; the training database is obtained by testing a photovoltaic board within a month and the mode between input and output of the neural network is recorded. The properties of photovoltaic panels also change over time, which means that neural networks must be trained regularly to ensure accurate MPPT.

\section{Results and Discussions}

In this study, we use Matlab/Simulink as a means to model and simulate our systems. The objective is to simulate the photovoltaic generator using the MPPT command to compare the efficiency of all proposed algorithms. These results are presented in Table 3 for ease of understanding.
The results are formulated in Table 3 to facilitate understanding.

\section{Conclusion}

This article will analyze and explain in detail the different MPPT technologies. The pros and cons of these echnologies are discussed and the results are presented in Table 3 to facilitate understanding. This article also discusses the different factors that affect MPPT performance and panel types, which can be used as a quick guide to panel selection and MPPT technology for specific applications.

\section{Author's Contributions}

All authors also contributed to the preparation, preparation and implementation of the manuscript.

\section{Ethics}

This item is original. The author claims that this is not an ethical issue that may arise after the publication of this manuscript. 


\section{References}

Abdelsalam, A.K., A.M. Massoud, S. Ahmed and P.N. Enjeti, 2011. High-performance adaptive perturb and observe MPPT technique for photovoltaicbased microgrids. IEEE Trans. Power Electron., 26: 1010-1021. DOI: 10.1109/TPEL.2011.2106221

Algazar, M.M., H. AL-monier, H.A. EL-halim and M.E. El Kotb Salem, 2012. Maximum power point tracking using fuzzy logic control. Elect. Power Energy Syst. 39: 21-28.

Azadeh, S. and S. Mekhilef, 2010. Simulation and hardware implementation of incremental conductance MPPT with direct control method using cuk converter. IEEE Trans. on Industrial Electron., 58: 1154-1161. DOI: 10.1109/TIE.2010.2048834

Bennacer, E.1., M. Hassouni, W. Ourahou, A.H. Ayrir and A.G. Amrani, 2018. A Study of Efficient MPPT Techniques for Photovoltaic System Using Boost Converter. Int. J. Emerg. Elect. Power Syst.

Bodur, M. and M. Ermis, 1994. Maximum power point tracking for low power photovoltaic solar panels. Proceedings of the 7th Mediterranean Electrotechnical Conference, Apr. 12-14, IEEE Xplore Press, Antalya, Turkey, pp: 758-761. DOI: 10.1109/MELCON.1994.380992

Enslin, J.H.R., M.S., Wolf, D.B. Snyman and W. Swiegers, 1997. Integrated photovoltaic maximum power point tracking converter. IEEE Trans. Industrial Electron., 44: 769-773.

Faranda, R. and S. Leva, 2008. Energy comparison of MPPT techniques for PV Systems. WSEAS Trans. Power Syst., 3: 446-455.

Hiyama, T. and K. Kitabayashi, 1997. Neural network based estimation of maximum power generation from PV module using environmental information. IEEE Trans. Energy Convers., 12: 241-247.

Hiyama, T., S. Kouzuma and T. Imakubo, 1995. Identification of optimal operating point of PV modules using neural network for real time maximum power tracking control. IEEE Trans. Energy Convers., 10: 360-367. DOI: 10.1109/60.391904

Hohm, D.P. and M.E. Ropp, 2000. Comparative study of maximum power point tracking algorithms using an experimental, programmable, maximum power point tracking test bed. Proceedings of the Conference Record of the 28th IEEE Photovoltaic Specialists Conference, Sept. 15-22, IEEE Xplore Press, Anchorage, AK, USA, pp: 1699-1702. DOI: $10.1109 /$ PVSC.2000.916230

Kim, T.Y., H.G. Ahn, S.K. Park and Y.K. Lee, 2001. A novel maximum power point tracking control for photovoltaic power system under rapidly changing solar radiation, Proceedings of the EEE International Symposium on Industrial Electronics, Jun. 12-16, IEEE Xplore Press, Pusan, South Korea, pp: 1011-1014.

DOI: 10.1109/ISIE.2001.931613
Liu, F., S. Duan, F. Liu, B. Liu and Y. Kang, 2008. A variable step size INC MPPT method for PV systems. IEEE Trans. Industrial Electron., 55: 2622-2628. DOI: 10.1109/TIE.2008.920550

Mekhilef, S. and M.N.A. Kadir, 2010. Voltage control of three-stage hybrid multilevel inverter using vector transformation. IEEE Trans. Power Electron., 25: 2599-2606.

Midya, P., P.T. Krein, R.J. Turnbull, R. Reppa and J. Kimball, 1996. Dynamic maximum power point tracker for photovoltaic applications. Proceedings of the PESC Record 27th Annual IEEE Power Electronics Specialists Conference, (ESC' 96), pp: 1710-1716.

Noguchi, T., S. Togashi and R. Nakamoto, 2002. Short current pulse-based maximum-power point tracking method for multiple photovoltaic and- converter module system. IEEE Trans. Industrial Electron., 49: 217-223.

Salah, C.B. and M. Ouali, 2011. Comparison of fuzzy logic and neural network in maximum power point tracker for PV systems. Electric Power Systems Research, 81: 43-50. DOI: 10.1016/j.epsr.2010.07.005

Schoeman, J.J. and J.D. Van Wyk, 1982. A simplified maximal power controller for terrestrial photovoltaic panel arrays. Proceedings of the 7th IEEE Power Electronics Specialists Conference, Jun. 14-17, IEEE Xplore Press, Cambridge, MA, USA. DOI: $10.1109 /$ PESC.1982.7072429.

Ting-Chung, Y. and Y.T. Shen, 2009. Analysis and simulation of maximum power point tracking for photovoltaic systems. Proceedings of the 30th ROC Symposium on Electrical Power Engineering, Nov. 28 29, Taoyuan, Taiwan, pp. 92-96.

Van Wyk, J.D. and J.H.R. Enslin, 1983. A study of wind power converter with microprocessor based power control utilizing an over synchronous electronic scherbius cascade. Proceedings of the IEEE International Power Electronics Conference, (PEC' 83), pp: 766-777.

Vikrant, A.C., 2005. Automatic peak power traker for solar PV modules using dspacer software. Master Thesis, In Maulana Azad National Institute of Technology vol. Degree of Master Technology in Energy. Bhopal: Deemed University.

Wang, N.C., Z. Sun, K. Yukita, Y. Goto and K. Ichiyanagi, 2010. Research of PV model and MPPT methods in Matlab. Asia-Pacific Power and Energy Engineering Conference, Mar. 28-31, IEEE Xplore Press, Chengdu, China, pp: 1-4. DOI: 10.1109 /APPEEC.2010.5449468

Wasynczuk, O., 1983. Dynamic behavior of a class of photovoltaic power systems. IEEE Trans. Power Appl. Syst., 102: 3031-3037.

DOI: $10.1109 /$ TPAS.1983.318109 
WBG, 2017. Morocco: A shining example of going solar.

http://blogs.worldbank.org/arabvoices/fr/moroccoshining-example-going-solar

Wikipedia. Énergie au Maroc. https://fr.wikipedia.org/wiki/\%C3\%89nergie_au_Ma roc
Yuvarajan, S. and S. Xu, 2003. Photo-voltaic power converter with a simple maximum-power-pointtracker. Proceedings of the 2003 International Symposium on Circuits and Systems, May 25-28, IEEE Xplore Press, Bangkok, Thailand, pp: 399-402. DOI: $10.1109 /$ ISCAS.2003.1205040 